\title{
MULHERES, SABERES PRÁTICOS, RELAÇÕES DE GÊNERO E A FLORESTA
}

\author{
WOMEN, PRACTICAL KNOWLEDGE, GENDER RELATIONS \\ AND THE FOREST
}

\author{
Rubens Elias da SILVA* \\ Fernanda da Silva BONFIM ${ }^{* *}$ \\ Rogério Ribeiro de SOUZA***
}

\begin{abstract}
RESUMO: Este artigo discute o papel das mulheres coletoras de sementes na construção de saberes práticos a partir do contato cotidiano com a floresta, tendo como démarche as relações de gênero como ponto nodal para a reconstrução das divisões social e sexual do trabalho. O locus da pesquisa é a comunidade do Maguari, localizada no interior da Floresta Nacional do Tapajós, no município de Belterra, oeste do Pará. As coletoras de sementes desempenham o papel de apreender, dominar e usufruir os recursos disponíveis na floresta. Esse papel efetiva-se num saber-fazer transmitido ao longo de gerações de mulheres coletoras, pois o contato estreito com a floresta define uma a identidade do grupo social e lhes confere sentido de ser e existir. A propriedade comunitária da floresta - segundo nossa observação em campo - passa a ser constituída através de relações sociais de cooperação entre mateiros e coletoras de sementes. Essa associação é fundamental para que o trabalho de coleta se efetive e possa oferecer a entrada de capital necessário para a reprodução social e, também, assegure a permanência de populações vivendo dentro da floresta. A partir do que foi visto em campo, as diferenciações existentes nas relações de gênero emergem no sentido prático de tornar exequível as tarefas de trabalho dentro da floresta, eclodindo em estratégias sociais eficientes de cooperação entre gêneros, refletindo na prática reflexões discutidas pelo ecofeminismo.
\end{abstract}

Palavras-chave: Mulheres. Saberes práticos. Gênero. Cooperação. Floresta.

\begin{abstract}
This work investigates the role of women collectors of seeds in the construction of practical knowledge with demarche gender relations as a nodal point for the elaboration of this knowledge in inspite of sexual and social divisions of work. The locus of the research is the Maguari community, located inside of National Tapajós Forest, Belterra, Western of Pará. The collectors of seed play the role of learning, to master $\mathrm{n}$ and use the resources available in the forest. This role is effectivated in knowledge across generations. Therefore the close contact with the same wedge the identity of the social group and gives them the sense of being and existence. The community forest land area according to our observations are made through social relationships between foresters and collectors of seeds. This association to the work of collectors becomes effective and can provide the capital injection required for social production, and also ensures the permanence of populations living within the forest. From what has

\footnotetext{
* Professor Adjunto do Centro de Formação Interdisciplinar da Universidade Federal do Oeste do Pará (CFI - UFOPA). Doutor em Sociologia pelo PPGS - UFPB. E-mail: mytheores@yahoo.com.br.

** Graduanda em Ciências Biológicas pelo Instituto de Ciências da Educação da Universidade Federal do Oeste do Pará (ICED - UFOPA). Bolsista de Iniciação Científica pelo PROPPIT / UFOPA. E-mail: nandabonfim1@ hotmail.com.

*** Graduando em Ciências Biológicas pelo Instituto de Ciências da Educação da Universidade Federal do Oeste do Pará (ICED - UFOPA). Bolsista de Iniciação Científica pelo PROPPIT / UFOPA. E-mail: rogermat13@hotmail.com.
} 
been observed in the fieldwork is the existing differences in gender relations that emerge in the possible work tasks within the forest hatching in efficient social cooperation strategies between genders, reflecting discussions about echofeminism.

Keywords: Women. Practical knowledges. Gender. Cooperation. Forest.

\section{Introdução}

Este artigo é fruto das reflexões teóricas oportunizadas pela pesquisa do projeto de iniciação científica "Técnicas de manejo de sementes na Floresta Nacional do Tapajós entre mulheres coletoras e a construção de percepções acerca de práticas sustentáveis no espaço natural", apoiado pelo PROPITT/UFOPA. O objetivo do artigo é investigar o papel das mulheres coletoras de sementes na construção de saberes práticos a partir do contato cotidiano com a floresta, tendo como démarche as relações de gênero como ponto nodal para a construção desse saber - imprescindível para a obtenção dos recursos disponíveis na floresta. Desse modo, o que nos orientou como problemática de investigação foram três indagações, a saber: como os saberes práticos são construídos e constituídos pelas coletoras de sementes, numa perspectiva de gênero? Por que a colaboração entre homens e mulheres no processo de coleta se faz necessária para a vida em grupo? Por fim, de que modo as relações de gênero, e seus mecanismos de diferenciação e dominação, estabelecem redes de cooperação?

O locus da pesquisa é a comunidade ribeirinha do Maguari, localizada no interior da Floresta Nacional do Tapajós, no município de Belterra, oeste do Pará. Esta floresta é uma Unidade de Conservação Federal administrada pelo ICMBio, criada em 1974, numa área de 544 mil hectares, cobrindo quatro municípios. Na FLONA do Tapajós vivem cerca de nove mil moradores em vinte e nove comunidades, entre elas, o Maguari. A metodologia empregada foi a observação participante de modo a oportunizar uma verticalização dos investigadores no mundo social do trabalho das coletoras e, assim, ser possível a construção de uma etnografia sobre "mulheres da floresta". A partir das observações em campo, foram discutidas as questões referentes sobre a construção dos saberes práticos através da mediação de gêneros numa perspectiva socioantropológica. A observação das atividades dos atores sociais "em campo" deu-se a partir de descrição etnográfica, que compreende na busca da compreensão das manifestações culturais do outro, em seus mais variados aspectos socioculturais (GEERTZ, 1973). 
Foram aplicados dois questionários na comunidade do Maguari: o primeiro questionário teve como objetivo sondar dados socioeconômicos dos entrevistados; o segundo, o aberto, estendeu questões mais focadas no tema da pesquisa. As entrevistas foram norteadas tomando como base o diálogo, no sentido de construir laços de confiança entre pesquisador e interlocutores. Foram consultadas três mulheres coletoras de sementes na floresta, que compreendem a faixa etária entre 31 a 60 anos. Essas mulheres trabalham em média vinte anos na coleta de sementes, sendo que uma delas precisou se deslocar um período para Manaus para trabalhar, o que sinalizou períodos de crise na atividade. A ocupação principal de todas elas é a coleta de sementes. A renda mensal das mesmas oscila entre um e três salários mínimos. Devido ao fato de viverem numa área de Unidade de Conservação - todas vivendo em terra firme.

Tendo por espaço de investigação a floresta, a pesquisa teve como foco de trabalho as coletoras de sementes, mulheres que têm no seu trabalho a principal fonte de renda para o sustento da família. Foram registradas as histórias envolvendo o trabalho, o início na atividade de coleta, as dificuldades e habilidade cognitiva para mapear os espaços e sinais da floresta (CHAVES, 1997), fundamentada num saber para lidar com os riscos e perigos ali presentes. A tarefa da coleta de sementes envolve representações simbólicas, conhecimentos intergeracionais, adaptações às mudanças impostas pelo meio, adquiridos num processo social de aprendizagem. Com efeito, a integração dos pesquisadores na vida dessas mulheres foi determinante para o levantamento de dificuldades e conflitos existentes para que estas pudessem se construir como sujeitos, tomando como referência as relações de gênero a fim de compreender as particularidades do grupo investigado, suas práticas e simbolismo investido na organização do mundo social (DEBERT, 2011; NADEL, 2010). Vale salientar que essa integração dos pesquisadores deu-se de modo a serem capazes de levantarem e comunicarem experiências de vida que vão além da trajetória particular das vidas dessas mulheres, oportunizando o desencobrimento de práticas e discursos que dão sentido ao trabalho (ALBERTI, 2004; ESPINHEIRA, 2008), entendido como a esfera mais importante da dimensão da vida social.

A vida das mulheres que labutam na coleta de sementes faz parte de um contexto social e histórico da comunidade, pois esta atividade é fundamental para a reprodução social dos moradores dada as limitações específicas a atividades de exploração dos recursos da floresta e do rio, arbitrada por lei federal que rege as UCs. 


\section{Mulheres e a floresta: saberes práticos}

Inúmeras pesquisas apontam a importância da presença dos povos tradicionais na floresta amazônica como meio de conservação e preservação da mesma e, ao mesmo tempo, a garantia de reprodução do sistema social e cultural dos povos aí existentes (CASTRO, 2000; DIEGUES e MOREIRA, 2001; BENCHIMOL, 1999). Sem dúvida, as coletoras de sementes desempenham o papel de apreender, dominar e usufruir os recursos disponíveis na floresta. Esse papel, segundo nossa investigação, efetiva-se num saber-fazer transmitido ao longo de gerações de mulheres coletoras, constituindo um processo de etnomanejo - fundamental para o conhecimento da organização e regime da floresta - pois o contato estreito com a floresta define a identidade do grupo social e lhes confere sentido de ser e existir.

Entende-se, por etnomanejo, as estratégias de uso e preservação dos recursos aqui delimitados como os da floresta - disponíveis de modo a garantir a reprodução social da comunidade e a conservação da floresta. A convivência das coletoras de sementes com a floresta dá-se através da mediação de um acordo com os homens (mateiros) da comunidade, pois as mesmas enxergam este espaço natural como perigoso e hostil, contato este efetuado dentro de uma "divisibilidade crítica". Referimo-nos à divisibilidade crítica como a característica de a floresta ser e poder ser demarcada, mas a dinâmica própria do bioma redunda na incerteza na localização não só das zonas produtivas (McKEAN e OSTROM, 2001), mas até do próprio trajeto de volta para a comunidade (aprofundaremos a questão adiante).

Compreendemos a atividade da coleta de sementes para a confecção de artefatos (bijuterias) requer determinadas habilidades cognitivas, verdadeiros cadeias de esquemas práticos de percepção que funcionam como instrumento de construção da realidade e divisão do universo em que elas se movem (BOURDIEU, 1999). Dito isto, as coletoras de sementes aprendem desde cedo a identificar as sementes mais resistentes, onde encontrar, em qual período do ano, período de perecibilidade; essa percepção opera no sentido de tornar a atividade possível, o que engendra um conhecimento profundo a respeito das dinâmicas ecossistêmicas da floresta, que se denomina etnoconhecimento. Os riscos da floresta (insetos, mamíferos, queda de árvores, entre outros) possibilita uma divisão sexual do trabalho, elencando homens à incumbência de descobrir novos pontos de coleta e, principalmente, ir à frente das mulheres nos dias de coleta, abrindo caminhos e alertando-as de possíveis cuidados a tomar ao longo da trilha. O quadro a seguir explicita a divisão social do trabalho da 
coleta de semente via relações de gênero e que descreve, por assim dizer, uma racionalidade prática que separa trabalho "pesado" para os homens e o "leve", para as mulheres:

Tabela 1: Trabalho - atribuições sociais por gênero

\begin{tabular}{c|c|c|c}
\hline & $\begin{array}{c}\text { Atribuição da busca } \\
\text { de novos pontos de } \\
\text { coleta }\end{array}$ & $\begin{array}{c}\text { Atribuição da tarefa } \\
\text { de coleta das } \\
\text { sementes }\end{array}$ & $\begin{array}{c}\text { Atribuição de traçar } \\
\text { caminhos ao longo } \\
\text { da trilha na floresta }\end{array}$ \\
\hline Masculino & $\mathrm{x}$ & & $\mathrm{x}$ \\
\hline Feminino & & $\mathrm{x}$ & \\
\hline
\end{tabular}

A propriedade comunitária da floresta passa a ser constituída, grosso modo, através de relações sociais de cooperação. A construção do espaço social organiza as práticas e as representações dos agentes, vistas aqui enquanto atividades de coleta de sementes, que passam a operar numa rede complexa de sentidos e significados obtidos a custo de um trabalho árduo e intenso (BOURDIEU, 1999). Segundo a própria fala das coletoras, sem a cooperação de outros agentes (os homens) na etapa da coleta - que não participam diretamente da confecção das bijuterias - tornar-se-ia inviável a atividade, em termos práticos, pois, como dissemos anteriormente, a tarefa é dividida seguindo princípios de trabalho pesado - atribuição masculina - e trabalho leve, feminina.

Com isso, a ação das coletoras de sementes é mediada por um projeto cultural o que as torna sujeito da e na floresta - que ordena a experiência prática, o cotidiano e a relação precípua entre eles (SAHLINS, 1976). As relações entre coletoras e espaço natural têm como objetivo a obtenção de recursos da floresta para beneficiamento e venda desses recursos como objetos artesanais (pulseiras, brincos, cordões, pingentes). Assim, a extração desses recursos objetiva a comercialização de pequena escala, tendo como principais clientes as pessoas que visitam a FLONA ao longo do ano. Os critérios que definem o valor comercial das sementes - resultando no valor de troca dos objetos artesanais - são dureza das sementes, dificuldade para encontrá-las na floresta e valor estético. Quanto mais duras, as sementes oferecem mais resistência ao desgaste ao longo do tempo; quanto mais difíceis de serem encontradas, mais incidirá no seu valor de troca final. Por último, o critério estético imprime valor às peças, o que sugere, par excellence, que as determinações concretas de sua obtenção têm mais proeminência no valor final que as sugestões estéticas. 
Após a obtenção das sementes, o beneficiamento das mesmas passa por algumas etapas fundamentais: coleta das sementes, retirada da "embalagem", processo de cozimento das sementes - para a sua conservação - por três minutos, secagem e confecção das artesanias. De acordo com a observação em campo, pode-se afirmar que o impacto ambiental dessa atividade coletora é mínimo, ao mesmo tempo desempenha um importante vetor de captação de recursos financeiros para a reprodução social das famílias envolvidas. Com isso, informa que o manejo das sementes permite um modelo de sustentabilidade centrado em critérios socialmente referidos no tocante ao conhecimento local sobre as dinâmicas da floresta e os ritmos da natureza (LENZI, 2006). Constrói-se, a partir daí, um modelo de sustentabilidade que é tecido a partir de complexas relações entre agentes sociais e o meio natural, a saber, tipos de árvores e arbustos, sucessão de estações, regimes lunares, etc.

Tabela 2: Divisão do ano a partir da disponibilidade das sementes na floresta

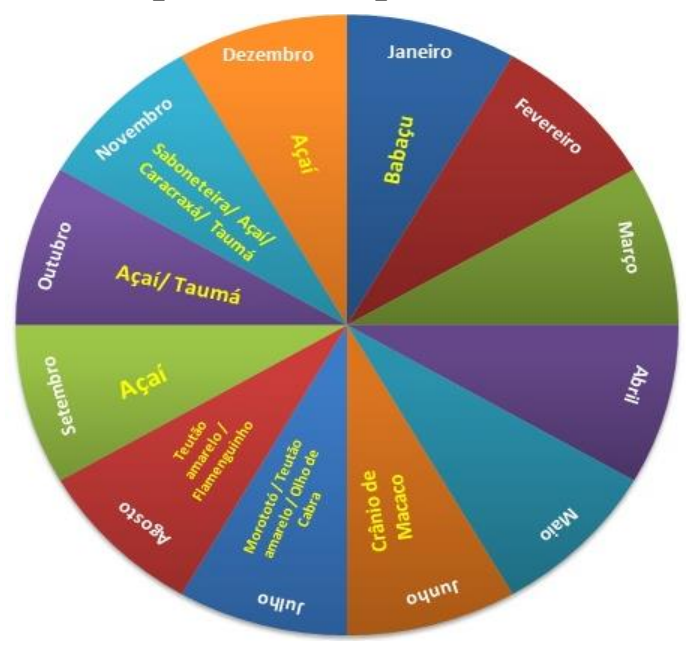

O espaço da floresta e sua correspondente "humanização" desdobra-se numa relação de fixos e fluxos, altamente variantes, tomando como empréstimo as reflexões sobre o espaço segundo Santos (2008). O universo do saber prático, seus encaminhamentos e realizações no cotidiano, é efetivado no sistema do pensamento (cognição) e ação, estando a floresta como espaço que dá sentido a esses engajamentos. Assim, os fluxos incorporam a dominação do espaço da floresta, seu entendimento e interpretação; a ação transformadora das coletoras na floresta incorpora o processo de retirar, descartar e selecionar novas sementes para o trabalho artesanal. Já os fixos compreenderiam a floresta, espaço onde a biodiversidade estabelece diálogo com o culturalizado: os agentes e seus fluxos. Com efeito, eclode daí a sociobiodiversidade das 
mulheres da floresta, que nomeiam, classificam, domesticam a riqueza do espaço natural, culturalizando-o num continuum no processo histórico (DIEGUES, 2000).

Sem dúvida, esses saberes práticos constituem importante acervo cultural dos moradores do Maguari, tendo nas mulheres a protagonismo na arte de confeccionar produtos a partir das sementes encontradas nos meandros da floresta. Deve-se pontuar, também, que esse acervo cultural é transmitido oralmente, ligando uma geração à outra no cuidado, aprimoramento e transmissão desse etnoconhecimento. Ademais, a relação estabelecida com a floresta é permeada num conjunto de valores éticos e morais, orientando quando e como explorar os recursos aí existentes. Em outro trabalho socioantropológico, podemos verificar a existência de um código moral para obter os recursos do manguezal, entre as mulheres marisqueiras (SILVA, 2011). Conclui-se, então, que as populações tradicionais que mantém uma relação estreita com o espaço natural, enxergam-no além da sua dimensão material, resultando num saber prático que aglutina as esferas do material e do invisível que compõem a realidade social (GODELIER, 1981).

\section{Gênero e trabalho: cooperando somos mais}

O trabalho das coletoras e o auxílio de homens na conservação dessa atividade revela que a dimensão laboral incide, via de regra, em relações sociais de gênero. A atribuição de atividades específicas segundo graus de "periculosidade e risco", informa que estes possuem aspectos relacionais e culturais da construção social do labor masculino e feminino (HEILBORN e SORJ, 1999). Desse modo, a forma como as coletoras se concebem executando a atividade e atribuindo "valorações sociais" como perigo conduz-nos a afirmar que esta valoração corresponde ao universo cultural, inscrito num dado histórico das relações de gênero - masculinidade/feminilidade (WOORTMANN, 1991; WOORTMANN, 1998).

É necessário afirmar que as condições dadas à nossa observação em campo das atividades da coleta de sementes fez-nos considerar relevante a noção de gênero como categoria fundante das relações sociais que cobrem, a priori, o conjunto da vida social. A construção dos saberes práticos para extrair os recursos disponíveis na floresta obedece a critérios culturais de gênero que delegam labores a mulheres e homens, interligando-os à vida ativa. Às mulheres, cabem a tarefa de colher as sementes, selecioná-las, cozê-las e manufaturá-las para a comercialização ulterior. Seriam consideradas, grosso modo, atividades que requerem perícias atribuídas culturalmente 
ao feminino. Aos homens, as atividades rudes, das mãos, em princípio: portar facões, cortar galhos de árvores ou arbustos que obstruam a trilha, matar animais peçonhentos, entre outros.

Woortmann (1991) ao estudar o tempo e o espaço construídos pelas mulheres em comunidades pesqueiras, considerou estas duas categorias em criadoras de sentido na construção de identidades e gêneros, classificando os espaços sociais de domínios pertinentes a homens e mulheres. No Maguari, conforme a observação de campo, podese sugerir que as relações de gênero possuem certa similitude ao que foi debatido por Woortmann, uma vez que as relações de produção reconstroem as politicas de gênero consolidadas em âmbito doméstico. Mas essa reconstrução das relações de produção, via relações de gênero, instaura um novo espaço delegado às mulheres, seguindo duas frentes distintas: a primeira, de que o trabalho das coletoras de sementes é importante para o orçamento doméstico, o que sinaliza a precariedade do salário obtido pelo trabalho masculino e a complementaridade econômica entre gêneros para a organização das despesas da casa, fenômeno social presente em outros espaços como manguezais (DANTAS, 2012), mulheres indígenas, no Tocantins (MILHOMEM, 2012), seringais no Acre (WOORTMANN, 1998). A segunda, a emergência da figura da mulher enquanto sujeito ao produzir mercadorias capazes de assegurar a autonomia pessoal e reprodução social dos grupos em que estão inseridas.

Com efeito, as relações sociais desenvolvidas com o contato direto com a floresta, açambarcada dentro de um etnoconhecimento e manejo tradicional, proporciona a visualização das relações de gênero versus espaço natural como dimensão necessária para a compreensão da floresta como espaço socializado e vivido. Sendo assim, a relação que as mulheres coletoras estabelecem com a floresta, o saber-fazer construído através do intenso contato, a habilidade de tratar as sementes, descascá-las, cozê-las, confeccionar os artigos indumentários (brincos, colares, pulseiras, entre outros), e o respeito com as árvores e os animais possibilita pensarmos na corrente teórica ecofeminista.

O ecofeminismo é um movimento social que inaugura nos anos noventa do século passado a elaboração de princípios e ética para os seres humanos em relação ao meio ambiente. Este movimento político opera no sentido de pensar a mulher e a natureza como vetores de práticas sociais alternativas às formas de opressão social, historicamente delegadas e agenciadas pelos homens (DI CIOMMO, 1999). Desse modo, a forma como as mulheres se relacionam com a natureza e os dispositivos de 
negociações estabelecidos com os homens constrói um novo conceito para as relações de gênero, uma vez que:

O ecofeminismo sugere [...] o reconhecimento de que, apesar de o dualismo natureza-cultura ser um produto da cultura, podemos conscientemente escolher a aceitação da conexão mulher-natureza, participando da cultura, reconhecendo que a desvalorização da doação da vida tem consequências profundas para a ecologia e as mulheres (KING, 1989, p.24).

Esse movimento político e social foca-se detidamente na relação da mulher com a natureza e os saberes que daí resultam. Em A Dialética do Esclarecimento, Adorno e Horkheimer apontam que o processo histórico e cultural do homem, ao se separar da natureza através do uso da ratio, domina a natureza para dela explorar os recursos ate à exaustão e, em seguida, o domínio opressor da mulher no âmbito das relações sociais no nível público e doméstico (ADORNO e HORKHEIMER, 1970). O que Morin denunciou como essa dominação gerou sujeição e novos processos de manipulação e subjugação dos humanos pelos humanos, cada vez mais o campo da técnica ditando o ritmo social à lógica do matadouro (MORIN, 2010). É contra esse racionalismo que o movimento ecofeminista se volta: o movimento iluminista, ao observar a natureza apenas em sua objetificação e reificação, redundou numa sistemática depredação e/ou destruição de ecossistemas em todas as partes do globo. Por isso,

$\mathrm{O}$ ecofeminismo trabalha com o conceito de gênero, e afirma que a mulher não é apenas diferente do homem, mas é distinta, dada a sua experiência concreta de vivência da condição feminina, que define a experiência, porque o enraizamento biológico origina e confirma a experiência social do gênero feminino, o que é reconfirmado na socialização e repassado pela predisposição genética (DI CIOMMO, 2003, p. 424).

Com isso, as coletoras de sementes, com seus saberes práticos utilizados para desbravar e reconhecer a densa floresta, reforçam a sensibilidade, a solidariedade e o zelo - socialmente cultivados e estimulados, numa perspectiva de gênero - pelo espaço natural.

\footnotetext{
Essa postura cuidadosa e respeitosa pela floresta como espaço que assegura a sobrevivência do grupo e facilitador de ações sociais culturalmente relevantes, vivenciadas por mateiros e coletoras de sementes pode dar a chave para compreendermos como esse saber prático instaura uma ecologia nova, onde aqueles buscam valores essenciais que deem sentido à civilização (DI CIOMMO, Idem, p. 438).
}

Neste sentido, a associação entre mateiros e coletoras de sementes é fundamental para que o trabalho de coleta se efetive e possa oferecer a entrada de capital necessário para a reprodução social e, também, assegure a permanência de populações vivendo dentro da floresta. Assim, essa atividade aponta a complementaridade (WOORTMAN, 
1991) entre homens e mulheres como necessária para a realização e recriação de saberes práticos. A partir do que foi visto em campo, as diferenciações existentes nas relações de gênero emergem no sentido prático de tornar exequível as tarefas de trabalho dentro da floresta, eclodindo em estratégias sociais eficientes de cooperação entre gêneros. Ademais, podemos sugerir que a divisão sexual do trabalho - com suas gradações entre pesado e leve - dá-se na esfera da consciência prática (GIDDENS, 2009), pois implica em ações que visam benefícios coletivos e atribuem tarefas segundo limitações físicas por gênero. Desse modo, as relações de gênero entre coletoras de sementes e mateiros estabelecem-se através de práticas sociais negociadas visando à integração social da comunidade e a dominação prática dos recursos disponíveis na floresta. A pesquisa possibilitou-nos compreender como se desencadeiam as práticas sociais em populações tradicionais que vivenciam cotidianamente relações sociais estreitas com a floresta - a comunidade do Maguari, na FLONA Tapajós -, incluindo aí os saberes práticos que constituem a díade - a outra, o espaço natural - do conceito de sociobiodiversidade.

Acrescenta-se, ainda, como as relações de gênero são reconstruídas, assumem novos significados sociais no devir histórico e que, no caso das coletoras de sementes do Maguari, apontam novas performances sociais em contextos culturais historicamente dominados pelos homens.

\section{Referências}

ALBERTI, Verena. Ouvir contar: textos em história oral. Rio de Janeiro: Editora FGV, 2004.

BENCHIMOL, Samuel. Amazônia: formação social e cultural. Manaus: Valer, 1999.

BOURDIEU, Pierre. Razões práticas: sobre a teoria da ação. Campinas/SP: Papirus, 1996.

CASTRO, Edna. Território, biodiversidade e saberes de populações tradicionais. In: DIEGUES, Antonio C. (org.). Etnoconservação: novos rumos para a proteção da natureza nos trópicos. São Paulo: NUPAUB/USP - Hucitec, 2000. p.165-180.

CHAVES, Maria do Perpétuo Socorro R. Representações da natureza: os avisos da mata e os significados do rio. In: LIMA, Jacob C et al (org.). Trabalho, sociedade e meio ambiente. João Pessoa: Edufpb, 1997. p. 213-223.

DANTAS, V. M. C. Salmeron. Nas marés da vida: histórias e saberes das mulheres marisqueiras. p.159-169. In: LEITÃO, Maria do Rosário F. A. e CRUZ, Maria H. S. Genero e trabalho: diversidades de experiências em Educação e comunidades tradicionais. Florianópolis: Ed. Mulheres, 2012. 
DEBERT, Guita G. Apresentação. In: FERIANI et al. Etnografia, etnografias. São Paulo: Annablume, 2011. p. 7-11.

DI CIOMMO, Regina C. Relações de gênero, meio ambiente e teoria da complexidade. 2003.

Regina C. Ecofeminismo e educação ambiental. Uberaba: Ed. Universidade de Uberaba / São Paulo: Conesul, 1999.

DIEGUES, Antonio C. e MOREIRA, André de C. Apresentação. In: DIEGUES, Antonio C. e MOREIRA, André de C. Espaços e recursos naturais de uso comum. São Paulo: NUPAUB/USP, 2001. p. 9-13.

ESPINHEIRA, Gey. Metodologia e prática de trabalho em comunidade: ficção do real observar, deduzir e explicar: esboço de metodologia de pesquisa. Salvador: Edufba, 2008.

GEERTZ, Clifford. The interpretation of cultures. Princeton: Basic Books, 1973.

GIDDENS, Anthony. A constituição da sociedade. São Paulo: Martins Fontes, 2009.

GODELIER, Maurice. O visível e o invisível entre os Baruya da Nova Guiné. In: CARVALHO, Edgard de A. (org.). Godelier. São Paulo: Ática, 1981.

HEILBORN, Maria L; SORJ, B. Estudos de gênero no Brasil. In: MICELI, S. (org.). O que ler na ciência social brasileira - sociologia. São Paulo: Editora Sumaré, 1999.

HORKHEIMER, M; ADORNO, T. Dialéctica del Iluminismo. Buenos Aires: Editora Sur, 1970.

KING, Y. The ecology of feminism and the feminism f ecology. In: PLANT, J. Healing the wounds: the promise of feminism. Londres: Green Print, 1989.

LENZI, Luciano. Sociologia ambiental: risco e sustentabilidade na modernidade. Bauru/SP: Edusc, 2006.

McKEAN, M. e OSTROM, E. Regimes de propriedade comum em florestas: somente uma relíquia do passado. In: DIEGUES, Antonio C. e MOREIRA, A. C. (org.). Espaços e recursos naturais de uso comum. São Paulo: NUPAUB/USP, 2001.

MILHOMEM, Maria Santana F. S. Mulheres indígenas, sim. Professoras, por que não? Estudo sobre as representações de gênero e poder na comunidade Xerente. P.57-68. In: LEITÃO, Maria do Rosário F. A. e CRUZ, Maria H. S. Gênero e trabalho: diversidades de experiências em Educação e comunidades tradicionais. Florianópolis: Ed. Mulheres, 2012.

MORIN, Edgar. Ciência com consciência. Rio de Janeiro: Bertrand Brasil, 2010. 
NADEL, S. F. Compreendendo os povos primitivos. In: FELDMAN-BIANCO, B (org). Antropologia das sociedades contemporâneas. São Paulo: Edunesp, 2010.

SAHLINS, Marshall. Culture and practical reason. Chicago: Chicago Press, 1976.

SANTOS, Milton. Técnica, espaço, tempo. São Paulo: Edusp, 2008.

SILVA, Rubens E. Sob o olhar do Pai do Mangue: ensaio sociológico sobre a relação homem-natureza mediada por uma narrativa mítica. João Pessoa: Editora Ideia, 2011.

WOORTMANN, Ellen K. Da complementaridade à dependência: a mulher e o ambiente em comunidades "pesqueiras" do nordeste. Brasília, 1991.

Ellen K. Família, mulher e meio ambiente no seringal. In: NIEMAYER, Ana M; DE GODOI, Emilia Pietrafesa (org.): Além dos territórios: por uma troca entre etnologia indígena. São Paulo: Mercado das Letras, 1998. p. 1-50.

[Recebido: 08 dez. 2013 / Aceito: 25 mai. 2014] 